\title{
Cenas contemporâneas de escrita e leitura em revistas portuguesas de poesia: Telhados de Vidro
}

\author{
Ida Alves* \\ Beatriz Machado Conte Fonseca**
}

Resumo

Apresentação de mapeamento realizado sobre revistas de poesia portuguesas editadas a partir dos anos 90 do século XX, com destaque para Relâmpago, Cão Celeste e Telhados de Vidro. Reflexão crítica em relação a esse conjunto de revistas, visando configurar algumas cenas de escrita e de leitura que produzem, isto é, como podemos ler em suas páginas a produção, a circulação e a recepção crítica de/sobre poesia, além do modo como se articulam com o contexto cultural, social e político em que estão inseridas. Neste artigo, tratamos inicialmente da importância dos periódicos literários, comparamos brevemente os três títulos destacados para focalizar mais detalhadamente a revista Telhados de Vidro, dirigida pelos poetas Manuel de Freitas e Inês Dias. Reflexão sobre a produção poética portuguesa e a sua crítica, a relação com a sociedade contemporânea.

Palavras-chave:Poesia portuguesa pós-90 do século XX. Revistas de poesia. Crítica de poesia. Cultura contemporânea.

\footnotetext{
* Universidade Federal Fluminense(UFF). Professora Titular de Literatura Portuguesa. Docente do quadro permanente da PósGraduação Estudos de Literatura UFF. Colidera o Grupo de Pesquisa Poesia e Contemporaneidade - UFF/CNPq. É coautora de obras sobre poesia portuguesa moderna e contemporânea, além de diversos capítulos de livros e artigos publicados em revistas brasileiras e estrangeiras. https://orcid.org/0000-0002-6892-7289

** Universidade Federal Fluminense (UFF). Licenciada em Letras (Português / Literaturas). Foi Bolsista PIBIC/CNPq (20182020), no projeto Cenas de leitura: vozes e revistas portuguesas de poesia contemporânea, sob a orientação da Prof. Dra. Ida Alves (UFF). Integrou o Grupo de Pesquisa Poesia e Contemporaneidade, liderado pelas Profas. Celia Pedrosa e Ida Alves. https://orcid.org/0000-0002-6113-0875
} 


\title{
Contemporary scenes of writing and reading in Portuguese magazines poetry: Telhados de Vidro
}

\begin{abstract}
Presentation of mapping carried out on Portuguese poetry magazines published from the 90s of the 20th century, with emphasis on Relâmpago, Cão Celeste and Telhados de Vidro. Critical reflection in relation to this set of magazines, aiming to configure some scenes of writing and reading that they produce; how we can read in its pages the production, the circulation and the critical reception of / about poetry, in addition to how they articulate with the cultural, social and political context in which they are inserted. In this article, we initially dealt with the importance of literary periodicals, we briefly compared the three titles highlighted to focus in more detail on the magazine Telhados de Vidro, directed by the poets Manuel de Freitas and Inês Dias. Reflection on Portuguese poetic production and its criticism, the relationship with contemporary society.
\end{abstract}

Keywords: Post-90 Portuguese poetry of the $20^{\text {th }}$ century. Poetry magazines. Critiscism of poetry. Contemporary culture.

Recebido em: 27/09/2020 // Aceito em: 22/11/2020. 
De 2017 a 2020, desenvolvemos o projeto de pesquisa, apoio $\mathrm{UFF} / \mathrm{CNPq}$, intitulado Cenas de leitura: vozes e revistas portuguesas de poesia contemporânea, com o mapeamento e análise de revistas portuguesas de poesia impressas que começaram a ser publicadas a partir dos anos 90 do século passado, de modo a verificar como ocorre, na contemporaneidade, a veiculação e a recepção de/sobre poesia. Como parâmetros de escolha das revistas, consideramos: a editoria de poetas; a publicação contínua de números, ao longo de anos; a importância crítica de seus colaboradores, reconhecida entre aqueles que produzem ou leem poesia, além da venda em livrarias portuguesas mais dedicadas à poesia, em Lisboa e no Porto. Evitamos revistas acadêmicas ou revistas literárias sem dominância de poesia. Com esse recorte, na fase final do projeto, destacamos três títulos mais referenciados e provocativos no contexto literário português atual: Relâmpago (n. 1, de 10/1997), Telhados de vidro (n.1, de 11/2003) e Cão celeste (n.1, de 04/2012). As três continuam a ser publicadas até o momento, com periodicidade flutuante.

Ao estudo dessas revistas, somou-se também a análise renovada de determinadas obras críticas de poetas de maior interesse para os objetivos da pesquisa, cuja produção veiculada em livros, periódicos e jornais demarcam trajetos específicos de compreensão do lirismo moderno e contemporâneo, como Jorge de Sena (uma figura tutelar para muita poesia de agora), Joaquim Manuel Magalhães (com produção lírica e obras críticas muito invocadas por poetas que começaram a publicar nos anos 90), João Miguel Fernandes Jorge (na função dupla de poeta e crítico na área de artes plásticas), Pedro Mexia (também crítico em jornais), Manuel de Freitas (igualmente crítico, além de editor de revistas e livros de poesia) e Luis Quintais (que integra a direção 
da revista Relâmpago com o poeta Gastão Cruz). Buscamos compreender em seus trabalhos a situação da crítica de poesia em diálogo com o lirismo que se vem praticando nas últimas décadas, na qual a relação com o leitor e a proximidade com as circunstâncias cotidianas se evidenciam fortemente pelo diálogo com outros poetas e pessoas conhecidas, na anotação de situações diárias comuns e na constituição de determinadas estratégias de escrita e leitura, performatizando o que denominamos de "cenas de escrita e cenas de leitura", ou seja, realização de atos e gestos que determinam situações de escrita lírica e modos de ler poesia em nosso presente.

Portanto, em decorrência dos percursos reflexivos encetados, o projeto ora concluído com seus pontos de vista descritivo, analítico e crítico permitiu-nos (docentes, orientandos e interlocutores acadêmicos) pensar, com mais dados objetivos e comparativos em mãos, como certos poetas portugueses contemporâneos tratam tópicos recorrentes: a legibilidade do cotidiano, a comunicabilidade em poesia, a experiência conflituosa com o mundo atual (habitação precária das cidades, confrontos identitários, deslocamentos geográficos, mercado financeiro impondo comportamentos e transformações sociais causadas pelo neoliberalismo, com distopias, massificação de gostos e escolhas, aceleração eletrônica) e a crítica da cultura (o diálogo interartes, o hibridismo de práticas literárias e artísticas, a interrogação dos processos estéticos, formas de apropriação discursiva, a experiência virtual, a desvalorização da cultura e da educação). Essas revistas demonstram determinadas eleições líricas (demarcando tradições e apropriações) e modos de fazer e pensar poesia na atualidade, o que vale examinar e discutir. 
A importância das revistas literárias já tem sido objeto de alguns estudos referenciais. ${ }^{1}$ De fato, tais revistas (tanto as impressas quanto as eletrônicas, cada vez mais comuns), pela sua dinamicidade de produção, distribuição e preço relativamente acessível ao leitor comum, cumprem o papel de congregar leitores diferentes e apresentar o que se vai fazendo em seu entorno. As revistas de poesia constituem uma materialidade gráfica (isso é válido também para as eletrônicas) e demarcam determinados espaços de escrita e leitura lírica ao estabelecerem, na continuidade de seus números, uma comunidade de leitores, um diálogo interno entre poetas e entre textos, refletindo práticas discursivas, processos de criação, questões críticas diversas, convergências e divergências temáticas e formais.

Pesquisar as revistas literárias de um determinado tempo exige mais do que descrevê-las e catalogá-las, pois é necessário entendê-las em determinados contextos estético, social e ideológico, para traçar aos olhares futuros um mapa de intenções e tensões de um tempo coletivo. Essas revistas são, simultaneamente, um testemunho de posições e um laboratório de ideias, práticas e escolhas, ou seja, são espaços gráficos a serem percorridos para (re)conhecer um horizonte estéticocultural de uma época, de uma sociedade.

Efectivamente os periódicos são um testemunho elucidativo de uma época, do pulsar do tecido social, das suas contradições, das ambições e limitações que a rodeiam, dos mecenas, da cultura, em sentido lato, de uma determinada ordem social. São uma radiografia poderosa que nos permite diagnosticar com rigor um determinado período. (PIRES, 1986, p. 19)

\footnotetext{
1 Fundamental o estudo de Clara Rocha (1985) acerca das revistas literárias portuguesas do século XX (até anos 80) e, entre nós, destacam-se as pesquisas desenvolvidas pelo NELIC - UFSC, sobretudo os estudos da Professora Maria Lucia Camargo sobre as revistas brasileiras de poesia do final do século XX. Cite-se também o professor e investigador português Daniel Pires e seu muito útil "Dicionário das revistas literárias portuguesas do século XX" (1986). Ver referências ao final.
} 
No contexto português, já no século XIX, jornais e revistas literários foram determinantes para a publicação de obras que se firmariam como fundamentais, por exemplo, Viagens na minha terra, de Almeida Garrett, na Revista Universal Lisbonense (no ano de 1846), como também abrigaram polêmicas literárias, sociais, históricas e políticas. No século seguinte, destacaramse, no campo literário, importantes revistas de poesia e de crítica de arte como A Águia, Orpheu, Presença, Cadernos de Poesia, Árvore, Notícias do Bloqueio, entre outras, que reuniram em suas páginas tantas vozes poéticas hoje muito valorizadas e marcaram momentos determinantes da literatura e, especialmente, da poesia portuguesa moderna. Após os anos 70 , as revistas desse tipo continuaram a existir, mas sem maior solidez ou visibilidade. Passaram a dominar a cena de leitura literária os suplementos específicos ou mesmo publicações jornalísticas, como o Jornal de Letras, Artes e Ideias, de Lisboa, cujo número 1 é de março de 1981, o qual exerceu uma função divulgadora e crítica até certo momento incontornável. ${ }^{2}$

Nesse contexto, ocorreu, ao final da década de 90 (1997), a publicação de uma revista dedicada somente à poesia, sobretudo portuguesa, intitulada Relâmpago, ${ }^{3}$ criada por determinação testamentária do poeta Luis Miguel Nava, falecido em 1995. Ainda em edição, com 40 números publicados, ora apresenta dossiês que tratam de poetas fortes da tradição lírica portuguesa moderna pós-Pessoa, como Jorge de Sena, Sophia de M. B. Andresen, Carlos de Oliveira, António Ramos Rosa, Eugénio de Andrade, Fiama H. P. Brandão, Luiza Neto Jorge, Ruy

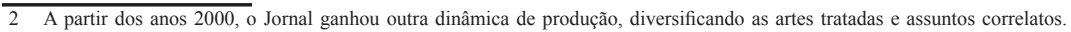
Embora continue sendo um valorizado jornal literário, a produção crítica sobre literatura cedeu páginas a outras artes e atividades culturais diversas, além de questões educacionais.

3 Ver o site com os sumários de cada número em https://www.relampago.pt/relampago-capas/index-relampago-capas.html . Os artigos não estão on line. O título é com letra minúscula.
} 
Belo, Herberto Helder, ora discute temas ligados às demandas contemporâneas como poesia e dinheiro, poesia e política, poesia e cinema (ou outras artes), o lugar e o ensino de poesia, além de número dedicado ao clássico imbatível, Camões, e ao notável filósofo português, Eduardo Lourenço. Seu sumário é composto de ensaios, testemunhos ou entrevistas (no caso dos números dedicados a poetas), poemas inéditos ou escolhidos e recensões críticas. Essas seções são praticamente fixas e os colaboradores convidados são poetas e ensaístas bem conhecidos. É uma revista que pode ser compreendida hoje como uma espécie de cartografia da poesia portuguesa do século $\mathrm{XX}$ apontando os nomes cimeiros e promovendo seu conhecimento e memória crítica. Abriu espaço para poetas novos dos anos 90, como demonstra a própria participação de Luis Quintais na direção, mas tem uma determinada compreensão do poético, valorizando a linguagem lírica, a metáfora, como relação exigente entre forma e conteúdo, o que significa não estarem presentes em suas páginas poetas com outro horizonte de trabalho. A discussão sobre poetas novos foi, aliás, tema de um dos seus números (12, 2003), também a poesia brasileira $(10,2000)$, mas não há em suas páginas enfoque crítico ou cultural mais aderente à vida cotidiana ou às questões política e econômicas que preocupam a sociedade portuguesa. Nota-se, por exemplo, a ausência de poetas fortes dos anos 70 como Joaquim Manuel Magalhães e João Miguel Fernandes Jorge. Por outro lado, Nuno Júdice, com lirismo acentuadamente metapoético e imagético, é poeta muito presente.

Pode-se considerar que essa revista assumiu um determinado cânone poético, reconhecido e valorizado pela crítica em geral. Oferece ao leitor ensaios de qualidade e trabalha para o 
conhecimento e visibilidade da produção poética portuguesa do século XX, "século de ouro", ${ }^{4}$ pós-Pessoa. É comercializada em muitas livrarias do país, o formato é de livro (16 x $24 \mathrm{~cm})$, com apoios do Ministério da Cultura, Direção Geral do Livro e das Bibliotecas e do Banco Português de Investimento. Interessa bastante ao leitor universitário (pesquisadores de Letras) pelos dossiês de poetas, pelos ensaios assinados por especialistas e materiais inéditos de poetas que, por vezes, traz a público.

As outras duas revistas destacadas na pesquisa, Cão Celeste e Telhados de Vidro, foram criadas por um mesmo casal de poetas, Manuel de Freitas e Inês Dias, sócios também da editora Averno, com um projeto editorial à margem das grandes editoras e livrarias comerciais, como se vê por seu catálogo de poetas que mescla poetas sobretudo pós-70, que não frequentam as páginas de Relâmpago, e poetas mais jovens, estreando-se ou publicando livros iniciais. Os livros editados pela Averno caracterizam-se pelo pequeno formato e projetos gráficos minimalistas ou artesanais. A editora está também nas mídias eletrônicas, com boa visibilidade entre os que acompanham a produção poética portuguesa contemporânea. As duas revistas citadas, com direção mais explícita de Manuel de Freitas, são realmente de grande interesse no panorama poético português contemporâneo e não apenas.

A Cão Celeste, a rigor, não é inteiramente uma revista de poesia, ou seja, o leitor constata que não há a publicação dominante de poemas, nem somente de estudos a respeito de obras poéticas. Compartilham também suas páginas textos sobre outros temas: sociais, políticos e culturais, com perspectiva

4 Fazemos referência indireta a uma grande e famosa (com o seu quê de polêmica) antologia publicada em 2002 com o título "Século de Ouro. Antologia Crítica da Poesia Portuguesa do Século XX", organizada por Osvaldo Silvestre e Pedro Serra. 
acentuadamente crítica e mesmo combativa ${ }^{5}$. Em relação ao poético, refletem sua inserção na cidade (na pólis) e questionam sua ação, sua resistência e habilidade de intervenção no campo das ideias. Os colaboradores unem-se por uma visada comprometida com o mundo contemporâneo e por relações de afeto, o que significa uma sensibilidade específica aos problemas que interessam à sociedade portuguesa; por tabela, a europeia. No texto de abertura do número 1, em tom próprio a Manuel de Freitas, afirma-se:

\begin{abstract}
Algures entre o jornal e a revista, o "Cão Celeste" pretende apenas ganir, ladrar com raiva ou paixão, amar ou odiar sem peias aquilo que o mundo quotidianamente lhe dá a ver. [...] Mas não somos um grupo, não obedecemos a qualquer cartilha literária ou política que possa servir para classificação geral. Este é, antes de mais, um espaço de encontro entre pessoas que ainda consideram urgente o livre exercício da crítica, do pensamento ou da revolta. E é justamente em nome dessa precária liberdade que prescindimos de qualquer apoio exterior, passível de condicionar os nossos gestos. [...] (A DIRECÇÃO, abr. 2012, p.3)
\end{abstract}

Criada em 2012 (portanto, mais recente que a Telhados de Vidro), o enfoque principal não é a poesia como produção de poemas, mas sim um pensamento crítico atento ao contemporâneo nas artes, na sociedade e na cidade, o que vamos chamar aqui de "po-ética". ${ }^{6}$ No que diz respeito à estruturação das seções, pode-se dizer que não há previsibilidade: a revista apresenta flutuação de colaboradores e hibridismo de gêneros textuais, isto é, trabalha com a ideia de deslocamento da posição

\footnotetext{
5 Como exemplo, citamos, no primeiro número, "Divagações sobre o futuro da literatura numa era de ignorância programada e pré-apocalíptica" (p.45 a 48); "A modernidade inquieta da parede da rua” (n.4, p. 47 a 52); "Daí a intraquilidade” (n. 13, p. 57 a 70)

6 Essa nomeação vem de leituras dispersas do que diz o poeta Michel Deguy, em entrevistas diversas, sobre a relação poesia e ecologia.
} 
passiva do leitor e a desautomatização da leitura. Cada número é de certa forma único. Há muitos poemas sim, há textos analíticos de escritas poéticas ou de outras artes, há textos que discutem fatos e ideias da sociedade portuguesa, da globalização, há textos ficcionais e recensões. Os colaboradores são poetas conhecidos como António Barahona (frequentemente) ou bem mais novos, que vão se firmando em seus trajetos de criação. Há ensaístas universitários bem referenciais nos estudos de poesia como Rosa Maria Marteloe Silvina Rodrigues Lopes. Háa invocação de certos poetas como Jorge de Sena, Herberto Helder, Joaquim Manuel Magalhães, que se tornam vozes muito significativas para o que Cão Celeste pensa e questiona. Há também um trabalho gráfico constante e muito cuidadoso, com diversas imagens (desenhos, ilustrações) originais e fora do lugar comum, em preto e branco, matizes de cinza, capas ilustradas, variando a cor, evitando um padrão único, rotineiro. O conjunto de números (até 2019, foram 13) estabelece uma espécie de tribuna para emissão de opiniões, apresentação de perspectivas e constituição de debates, torna-se, podemos dizer, um espaço "ágora" na cidade. Não esqueçamos de que Cão Celeste assume o filósofo Diógenes como um emblema. De fato, é uma das mais instigantes revistas de poesia ou do poético da atualidade portuguesa, com independência de posições e, ao mesmo tempo, estabelecendo uma cumplicidade "po-ética" entre seus colaboradores e leitores. ${ }^{7}$

Para essas duas revistas dirigidas por Manuel de Freitas e Inês Dias, a relação com os leitores é muito particular, uma vez que elas se oferecem como um espaço de abrigo para aqueles que não se conformam com a indústria cultural e com vida

7 Análise detalhada dessa revista foi realizada por Julio César Rodrigues Cattapan em sua tese de doutorado intitulada "MODOS DE RESISTIR: CINISMO E TESTEMUNHO NA REVISTA CÃO CELESTE” defendida em março de 2020, no PPG Estudos de Literatura da Universidade Federal Fluminense - UFF, sob orientação da Profa. Ida Alves. 
corrida / corroída na cidade contemporânea. Tais revistas não se encontram à venda em qualquer espaço, não são produtos impressos inertes em prateleiras comerciais de novidades. Quem deseja lê-las precisará buscá-las em espaços que tributam à poesia um olhar cuidadoso, as pequenas livrarias de rua, como casas de leitura frequentadas com vagar. As tiragens são restritas. Cão Celeste inciou-se com mil exemplares, mas baixou para 500 ou 350 exemplares. Telhados de Vidro começou com 500 exemplares e oscila em 350. Para conhecê-las, uma corrente de leitores de poesia que partilham ideias e insistem na leitura vagarosa e resistente a modismos, literatices e academismos. Esse posicionamento editorial significa um ato de resistência em face ao esvaziamento da Arte, que se torna, cada vez mais, numa sociedade neoliberal, mercadoria, submetendo-se, assim, às leis do capital, que privilegia a quantidade / utilidade e não a qualidade de criação. $O$ não acesso a seus conteúdos via rede on line, que possibilitasse maior acesso para além de Portugal, restringe a circulação de seus textos no Brasil, por exemplo, e acaba por se limitar a uma determinada comunidade de leitores que pode comprá-las pessoalmente. Outra questão relevante, uma vez que influencia diretamente a configuração de espaços de leitura e de escrita, é a presença recorrente dos mesmos colaboradores convidados, tanto no interior das próprias revistas, quanto, comparativamente, entre ambas: esses articulistas, poetas e críticos partilham pontos de vista frente aos problemas contemporâneos e às questões estéticas, o que não significa uma mesma posição ideológica ou reflexiva. Formam um grupo seleto unido por uma "política dos afetos", compreendendo o afeto com essa capacidade de tocar o outro, ser tocado, ou seja, partilhar pensamentos e ações por uma concepção crítica de/sobre o lugar 
da Arte e do artista hoje. Tais revistas (que, de certo modo, são complementares, uma com um viés mais literário, a Telhados de Vidro) e a outra mais plurifocal (Cão Celeste) apresentam um quadro - não tradicional e não canônico - de vozes críticas preocupadas com o tempo em que vivem e com as sociedades que se vão fechando em torno de valores mercadológicos e consumistas.

Contudo, nesta segunda parte do artigo, o destaque é dado à segunda revista, Telhados de Vidro (criada em 2003, com 23 números até o momento), por uma perspectiva socioliterária, com o fito de pensar qual (quais) cena(s) de leitura e de escrita essa revista reflete. O perfil dominante da revista é oferecer ao leitor um conjunto diverso da poesia portuguesa moderna e contemporânea, com publicação de poemas de poetas conhecidos, esquecidos ou à margem do movimento editorial (de diferentes idades) e de ensaios sobre a poesia em diferentes visadas. Além da poesia, há atenção também a outras Artes, como música e artes plásticas, cujo principal colaborador crítico, aliás, é o poeta João Miguel Fernandes Jorge. Nos vinte e três números examinados, observamos a presença de poemas em todos, o que não ocorre, por sua vez, com os ensaios (aparecem em 18 números ${ }^{8}$ ), as resenhas críticas (presentes em 14 números $^{9}$ ) e os textos literários/narrativos em prosa (presentes em 17 números ${ }^{10}$ ).

Ao fazermos o levantamento de dados, verificamos que, em relação à sua periodicidade, ela se assume na contracapa nãoperiódica. ${ }^{11}$ Esse posicionamento reflete, por um lado, a situação independente de apoios financeiros com sua exigência de prazos

\footnotetext{
Números: $1,2,3,4,5,6,7,8,9,12,15,16,18,19,20,21,22$ e 23.

Números: $5,6,7,8,12,13,14,16,17,18,19,20$ e 23 .

10 Números: 2,3,4,5,6,7,8,9,10,11,12,13,15,16,18, 21 e 22.

11 Há anos em que a revista é publicada duas vezes (exemplo 2008), porém há outros em que ela é publicada apenas uma vez (exemplo 2013). O último número (23) saiu em novembro de 2018. Isso não significa o fim de edição.
} 
estritos de publicação e, por outro, a configuração de como essa revista se constrói por meio de colaborações diversas que são encaminhadas aos editores sem prazo determinado e o fomento de expectativa por um novo número por entre os leitores fiéis. Nesse sentido, observamos o lugar referencial que essa revista conquistou, posto que apresenta uma longevidade - praticamente 17 anos - difícil de se encontrar em revistas desse tipo. Ainda em relação a esse aspecto, notamos que a revista não disponibiliza páginas para publicidade comercial. $\mathrm{O}$ que há, de fato, é o que denominamos divulgação cultural, isto é, ações do âmbito literário, por exemplo, da própria editora Averno, das livrarias Poesia Incompleta $^{12}$ (livraria que só vende livros de ou sobre poesia) e Paralelo $W^{13}$ (Manuel de Freitas é um dos sócios), bem como de edições de uma outra revista, chamada Intervalo. ${ }^{14}$ Telhados de Vidro não está disponível eletronicamente. É somente impressa, com formato 13 x 17,8 cm, capa cartonada, a cada número com cor e desenho diferentes, ilustrações ou colagens variadas, com cerca de 150 páginas, com os últimos números aumentando para 250 ou quase 300 páginas (o último, com 200 páginas), em formato livro. Há sobriedade associada à qualidade em seu arranjo gráfico. ${ }^{15}$ Tal sobriedade parece

\footnotetext{
12 Esta livraria foi criada em Lisboa e durou de 2008 até 2012, reabrindo, entretanto, neste ano (2018), no Brasil. Ver em https: $\leq / /$ www.jn.pt/artes/interior/livraria-poesia-incompleta-reabre-ja-ao-virar-da-esquina-9953564.html $>$.

13 Essa livraria ficava num apartamento na rua dos Correiros, n. 60, 1 esquerdo, mas encerrado o aluguel do espaço, agora é somente on line. "A livraria Paralelo W, criada em 2012 por um grupo de escritores e artistas plásticos, privilegia as pequenas editoras, sobretudo nas áreas da poesia e da ilustração, dispondo ainda de um espaço de alfarrabista com livros em segunda mão e primeiras edições. Neste espaço têm igualmente lugar exposições e leituras de poesia. "In https://lifecooler.com/artigo/ atividades/paralelo-w/436345/ A notícia do encerramento do espaço físico é dada ao final do n.13 da Cão Celeste.

14 Intervalo não é uma revista literária, e sim "de pensamento da actualidade" que "não visa de modo nenhum concorrer para a acumulação de saber pronto a consumir", deste modo o que une ambas a ponto de uma revista literária fazer a divulgação de uma que não o seja? Talves por dois s motivos que ao cabo confluem para um único, são eles: a) quando uma revista indica outra, ela estabelece com essa uma relação que pode ser de várias ordens, no presente caso, enxergamos a relação entre elas como ideológica, isto é, ambas pensam a modernidade ou o contemporâneo - como queiram - de maneira parecida. Assim, ambas,questionam o modo mercantil como a cultura vem sendo tratada pela sociedade contemporânea; b) esta relação de solidariedade ou partilha de ideias se reflete na presença de nomes que publicam tanto na Telhados de Vidro quanto na Intervalo, indicamos apenas alguns: José Miguel Silva, Rui Pires Cabral, Silvina Rodrigues e Manuel de Freitas.

15 Conforme afirma o poeta e artista plástico Luis Manuel Gaspar - que foi convidado, por vezes, a colaborar com as capas da revista -, na reportagem "Uma revista com qualidades" (QUEIRÓS, 2015), "tem uma lógica de sobriedade, de não ostentação,
} 
relacionar-se a dois aspectos: dar espaço de destaque ao poema como objeto impresso nas páginas; atrair um leitor realmente comprometido com a leitura de poesia.

Como todos os elementos presentes numa revista fazem parte de sua constituição identitária - uma vez que a identidade gráfica e de conteúdo se estabelece dentro de um contexto social e histórico -, a divulgação de publicações alheias também são significativas. Assim, a negação do fomento de qualquer instituição - inclusive, por meio de captação de recursos publicitários - faz parte do ideário dos editores que desejam, o quanto possível, não entrar na lógica mercantil de sujeição do espaço literário, em especial da poesia, à lógica de mercado consumidor de grandes livrarias comerciais. ${ }^{16}$ Ressaltamos, contudo, que, no momento em que se coloca no circuito de produção e venda - estabelecendo um valor pelo produto (o número mais recente custa 16 euros, valor alto se compararmos com outras edições de livros de poesia) -, a revista entra também no circuito e na lógica de compra e venda. Deste modo, por mais que a revista não adote, ou melhor, tente não se sujeitar a uma determinada lógica de mercado, é inevitável que, ao ser comercializada em outros espaços de venda, ela - bem como o seu conteúdo - vire um "produto que entra num circuito de consumo". ${ }^{17}$ Mas a forma de consumo é outra, já que exige leitura lenta e se dirige aos poucos interessados em poesia. ${ }^{18}$

Sobre a formação de um público leitor e, consequentemente, de espaços de leitura, é consequente observar a tiragem de uma revista, dado que tal número influencia na maior ou menor

mas é feita com um cuidado invulgar". Diferente de Cão Celeste, não há ilustrações ou desenhos no interior das páginas. Domina somente a mancha gráfica das palavras.

16 Esta política está muito presente na editora Averno, que não reedita os números dos livros por ela divulgados.

17 Clara Rocha, Revistas Literárias do século XX em Portugal, p. 137.

18 Comparem-se, por curiosidade, as tiragens dessas revistas com as de algum livro em prosa, romance, de escritores de muita visibilidade, nacionais ou estrangeiros, ligados a casas editoriais com maior fatia do mercado livreiro português. 
circulação da revista pelos ambientes. Quanto a Telhados de Vidro, em todos os números analisados, a tiragem é de 500 exemplares (exceto os números 18 e 19, com 350). Como sabemos, essa tiragem reflete duas questões que estão intimamente relacionadas: a) o investimento financeiro restrito; b) a certeza de o público leitor de poesia ser bem menor. A poesia não é "comercial", sobretudo o tipo de poesia que é publicada nessas revistas e, portanto, a própria revista demonstra a consciência de uma determinada cena de leitura: poucos se aproximam dessa produção, mas os que se interessam mantém um elo de fidelidade, entram numa comunidade de leitores, o que incentiva a continuidade da publicação. O n. 1 (nov. 2003, p.7) abre com a seguinte nota, não assinada, mas com o tom característico de Manuel de Freitas.

"A poesia não interessa" - e isso, como tudo, já foi dito. Acreditarão, alguns, no intervalo entre o dito e o nãodito. Depende dos casos.

Estamos todos sozinhos, mesmo os que nunca leram Rilke, Pessoa ou Larkin. A poesia - isso que não interessa - é uma forma primária e elaboradíssima de comunicação. Mas não temos um canal, uma razão suficiente ou sequer um prazo de validade. Também não gostamos de editoriais, números temáticos $\mathrm{e}$ comemorações subsidiadas pelas entidades competentes. A poesia, que não nos interesssa rigorosamente nada, move-nos de quando em quando. Temos de nos distrair da morte e não sabemos muito bem como. Talvez assim.

Ao não adotar também as mídias digitais para sua publicação integral, associa-se a um pensamento de resistência à massificação, à banalização e à sujeição da produção cultural a um suporte de leitura que incentiva a aceleração e a desatenção, pelo excesso de informações ou sua mistura sem critérios. Por outro lado, o acesso à revista somente pelo impresso dificulta a ampliação dos leitores, fora de Portugal. 


\section{Cenas contemporâneas de escrita e leitura em revistas portuguesas de poesia: "telhados de vidro"}

Outro item a se considerar na formação de leitores, é a publicação de poemas traduzidos de poetas estrangeiros. No caso do diálogo com a poesia brasileira, constata-se baixa presença de seus poetas ${ }^{19}$, que representam, aproximadamente, $5 \%$ do total de colaboradores da revista, embora, considerando o total de poetas estrangeiros, a presença brasileira seja a maior (representam, em média, $55 \%$ do total de colaboradores estrangeiros), dada a proximidade linguística e histórica. Ou seja, a revista acaba por reforçar - inclusive por não haver nenhuma recensão crítica de obras brasileiras - uma outra afirmação de Manuel de Freitas, em entrevista ao blog de poesia Escamandro:

Continua a haver um grande fosso entre Portugal e o Brasil. Os livros não circulam [...] Acabamos por ter um conhecimento bastante esporádico ou aleatório daquilo que, em matéria de poesia, se faz actualmente no Brasil. E devemo-lo (falo por mim) a contactos afectivos entre poetas de ambos os países $[\ldots]^{20}$. (FREITAS, 2017)

Ainda em relação aos laços luso-brasileiros, observamos que nas recensões críticas presentes na revista, que são uma espécie de valorização, bem como de estímulo para a leitura ${ }^{21}$ (ou, no caso dos CDs, para a escuta), não há indicação de nenhuma obra brasileira ${ }^{22}$, entretanto, observamos outras nacionalidades não europeias ou no limite europeu, como a chinesa, a turca e a eslovena, o que parece transmitir o ponto de vista de que é

\footnotetext{
19 Nomes brasileiros participantes: Pádua Fernandes, Fabiano Calixto, Fabio Weintraud, Luca Argel, Luis Maffei. Desses os mais publicados (média de 5 números) são Pádua Fernandes e Fabio Weintraub.

20 Disponível em: $\quad$ https://escamandro.wordpress.com/2017/12/10/um-fato-no-limite-da-nudez-entrevista-com-manuel-defreitas-por-fabio-weintraub/>.

21 "A recensão, além das suas funções pedagógicas e de convite à leitura contribui de modo decisivo, pela valoração negativa ou positiva que pressupõe, para a consagração ou esquecimento duma obra. Ela aumenta ou diminui, sem sombra de dúvida, o chamado leitor real, ou seja, o número de pessoas que efectivamente lêem o livro. Intervém portanto, de forma mais ou menos directa, no processo de recepção da obra literária, funcionando em muitos casos o crítico como intermediário entre a obra e o público" (ROCHA, p. 100).

22 A única referência a uma obra literária brasileira encontra-se no ensaio "Interferência e vazio (a partir da leitura de Telefunken e Pulsatilla) $-\mathrm{n}^{\circ} 16$, escrito por Silvina Rodrigues - que analisa alguns aspectos da poética de Luis Maffei (que já colaborou com a revista uma vez).
} 
mais necessário valorizar culturas distantes do que uma cultura próxima como a brasileira. Pode ser que a ausência de recensões de obras brasileiras se deva à escassez observada por Manuel de Freitas, porém, será que as obras - traduções - chinesas, turcas, eslovenas circulam mais do que livros brasileiros que já estão em português? Em outras palavras, não será isso um posicionamento deliberado frente a outra poesia de língua portuguesa?

Outro aspecto particular da revista - aliás, a Telhados de Vidro tem detalhes que fogem à ordem do convencional - é o modo como as informações pré-textuais estão organizadas, nisso incluímos os sumários e os textos de abertura. Estes, aliás, são raríssimos ${ }^{23}$ - presentes, apenas, no primeiro número e no décimo; os sumários pouco explicam acerca dos textos que virão, destacando, em geral, somente o nome dos colaboradores do número. Não há o recorte preciso de "seções" da revista que se repetiriam todo número, mas há uma parte inicial sempre intitulada "A antologia em .... (ano do número da revista)", bem como as resenhas críticas, denominadas "Efeitos Secundários". Se, para o leitor inicial, isso pode significar um território sem guia, pouco acolhedor, para o leitor independente, acostumado a conviver com a poesia, há uma liberdade de movimento bastante sedutor; o percurso de leitura pode ser feito como se desejar. Assim, a revista acaba por se constituir um lugar de encontro daqueles que fazem e pensam poesia com autonomia. Ao optar por uma circulação restrita, a revista aposta nesses leitores para os quais a poesia importa e resiste por não se submeter à secundarização comercial e cultural, nem se restringir a nomes consagrados e facilmente editáveis. Telhados de vidro, não tendo números temáticos nem edições consagradoras de poetas,

23 O que nos levou, como pesquisadores, a recorrer a entrevistas e conversas com os diretores dessa revista, publicadas em diversos locais, para melhor compreendermos o que esperam ou o que dizem acerca da Telhados de Vidro. 
manifesta um posicionamento crítico pelo silêncio e pela ausência. Os poetas que ali estão presentes com seus poemas ou seus textos críticos partilham uma ideia de defesa da poesia no cotidiano, cada vez mais despoetizado.

Voltando à questão estrutural da revista, como já referimos, ela não apresenta rubricas fixas em todas os números, além de deslocar constantemente a noção de gênero em poesia, uma vez que tanto há os poemas tradicionalmente compostos como textos em prosa em que o princípio poético se mantém. O leitor experimenta, de página a página, possibilidades textuais. Exigese dele ser "leitor em movimento". A flutuação e heterogeneidade de formas, temas e dicções, na revista, também está intimamente relacionada à pluralidade do contemporâneo. Quando um número apresenta todas as rubricas "recorrentes" da revista, registram-se cinco "zonas" de produção: 1- poemas em verso e em prosa de diversos nomes sem nenhum princípio crítico organizativo, por vezes apenas a ordem alfabética (essa parte recebe o título de “A antologia em .... (ano)". Por vezes, há um primeiro poema de poeta bastante conhecido quase como epígrafe do número; 2- poemas traduzidos de autores estrangeiros; 3- textos literários em prosa (que transitam entre gêneros) de diversos autores; 4textos ensaísticos - geralmente referentes à contemporaneidade e ao lugar da poesia, mas também textos sobre artes plásticas, bem como sobre determinados aspectos de uma dada dicção poética, de modo geral, relacionada a uma ideia de poesia na atualidade e, por fim, 5- recensões críticas ("Efeitos Secundários"). Notese que não há um número fixo de páginas destinadas à prosa, ao poema, ao ensaio e assim por diante, ou seja, numa dada edição pode ocorrer a publicação de três ensaios, ao passo que em outra, dois, ou até mesmo nenhum, visto que, como afirma 
Manuel de Freitas "Cada número é sempre uma incógnita: dos 20 ou 30 autores que convidamos, nunca sabemos qual vai ser ao certo o elenco final, nem o que iremos receber", isto é, "o convidado manda o que quiser, poema, ficção, ensaio, ele é que sabe"(QUEIRÓS, 2015). Assim, o leitor, que se adapta a - ou se identifica com - esse tipo de instabilidade, ao abrir a Telhados de Vidro, também sempre se surpreende e desloca seu movimento de leitura.

Em relação aos poetas presentes nessa revista, abrindo as tais "Antologia em...(ano)" tanto há nomes consolidados do século XX, como outros menos referidos: Mario Cesariny, Pedro Oom, José Amaro Dionísio, Luiza Neto Jorge, Jorge de Sena, Carlos de Oliveira, Fernando Assis Pacheco, Manuel de Castro, António José Forte, Ruy Cinatti, Eduardo Guerra Carneiro, Ângelo de Lima, Vitorino Nemésio, Ernesto Sampaio, Tomaz de Figueiredo, António Reis, António Ramos Rosa e Fátima Maldonado. Assim, essas escolhas significam uma espécie de reconhecimento da "malta". ${ }^{24}$ Ainda que os poetas sejam de décadas mais afastadas, o gesto de escolha ressalta o quanto atual é a poesia desse poeta, refletindo uma ideia de contemporaneidade. Como afirma Paula Cristina Costa - à luz, é claro, de Agamben - "será contemporâneo aquele texto ou autor que se consegue eternizar, ultrapassar as barreiras da data em que viveu e publicou, e projectar-se num sem tempo, num presente fora do tempo do aqui e do agora" (COSTA, 2015, p. 221). Vale ainda observar que os poetas vivos que vão sendo citados na revista também colaboram com ensaios críticos ou têm livros editados pela Averno ${ }^{25}$, o que reforça a ideia de que a revista, ao

\footnotetext{
$\overline{24}$ No português de Portugal, é frequente o uso desse termo para indicar companheiros, parceiros numa atividade em geral prazerosa.

25 Ver em $<$ http://editora-averno.blogspot.com/ $>$.
} 
reunir escritores de diferentes momentos, forma, como afirma Clara Rocha sobre as revistas literárias, um "palimpsesto de gerações" (ROCHA, 1985, p. 213). Em relação aos poemas, ao repetir em diferentes números a contribuição de mesmo poeta, acaba-se por constituir, para cada um, uma espécie de pequena antologia. Igualmente ao reunir poemas de diferentes poetas num número, sob o título "Antologia em ... (ano)", marca-se um gesto crítico significativo, já que são escolhidos. Desse modo Telhados de Vidro é uma cena crítica da poesia portuguesa, recortando certa produção que condiz com a ideia de Literatura defendida pela revista, como afirma Manuel de Freitas "Há um lado que está para lá do texto: só convidamos alguém cuja postura ética nos inspire alguma cumplicidade, e isto tanto vale para poetas como para ensaístas ou tradutores" (QUEIRÓS, 2015). Ou seja, forma-se uma cena de escrita que provoca uma cena de leitura, uma vez que "a revista literária ou de interesse literário é, por definição, um espaço de afirmação colectiva de criadores - a que podem juntar-se críticos literários, pensadores, homens de cultura ou artistas plásticos" (ROCHA, 1985, p. 85).

Se juntarmos todos os números dessa revista até o momento publicados, teremos uma grande antologia que apresenta ao leitor um cenário poético convergente com a "po-ética" defendida pelos seus diretores ou pequenas antologias determinadas por algumas ideias-chave que atravessam a coleção de números. Esse mesmo procedimento ocorre, por sua vez, na tradução de poemas de autores estrangeiros (seção muito valorizada pela revista). Essa preocupação de abrir a cena de leitura para além da língua portuguesa colabora para a oxigenação do tecido poético e para a formação mais aberta do leitor português de poesia. Não 
à toa Manuel de Freitas afirma em entrevista ${ }^{26}$ que "Nas revistas Telhados de Vidro e Cão Celeste, temos procurado (eu e a Inês Dias, além de outros tradutores assíduos) partilhar textos de autores pouco conhecidos ou valorizados em Portugal" 27. Como se vê no quadro a seguir, há vozes de diferentes países (apesar da predominância da Europa em relação ao continente americano) e de diferentes épocas (tais como poetas contemporâneos e os românticos alemães), mas que apresentam em comum, de modo geral, uma preocupação em pensar e interrogar a literatura e a linguagem.

\begin{tabular}{|l|l|l|}
\hline Diego Doncel & Espanha & Poema \\
\hline Konstandinos Kavafis & Grécia & Poema \\
\hline Malcolm Lowry & Inglaterra & Poema \\
\hline Thom Gunn & EUA & Poema \\
\hline Toni Montesinos & Espanha & Poema \\
\hline Elisa Biagini & Itália & Poema \\
\hline Marcial & "Império Romano" & Poema \\
\hline Djuna Barnes & EUA & Poema \\
\hline Dylan Thomas & Reino Unido & Poema \\
\hline Friedrich Hölderlin & Alemanha & Prosa (ensaio) \\
\hline Mariano Peyrou & Argentina & Poema \\
\hline Robert Schindel & Áustria & Poema \\
\hline Louise Glück & EUA & Poema \\
\hline Friedrich Hölderlin & Alemanha & Epigrama \\
\hline Schelling & Alemanha & Prosa (ensaio) \\
\hline Jules Renard & França & Excertos \\
\hline Ugo Foscolo & Grécia & Poema \\
\hline Fernando Arrabal & Espanha & Poema \\
\hline Ignacio Escuín Borao & Espanha & Poema \\
\hline Luis Alberto Cuenca & Espanha & Poema \\
\hline
\end{tabular}

\footnotetext{
26 Disponível em: <https://escamandro.wordpress.com/2017/12/10/um-fato-no-limite-da-nudez-entrevista-com-manuel-defreitas-por-fabio-weintraub/>. 
Cenas contemporâneas de escrita e leitura em revistas portuguesas de poesia: "telhados de vidro"

\begin{tabular}{|l|l|l|}
\hline Heinrich Von Kleist & Alemanha & $\begin{array}{l}\text { Anedotas e } \\
\text { narrativas }\end{array}$ \\
\hline Josep M. Rodríguez & Espanha & Poema \\
\hline Pablo Fidalgo Lareo & Espanha & Poema \\
\hline John Mateer & Austrália & Poema \\
\hline Amalia Bautista & Espanha & Poema \\
\hline Fábio Michieli & Itália & Poema \\
\hline Gerard Malanga & EUA & Poema \\
\hline Linda Maria Baros & Romênia & Poema \\
\hline Novalis & Alemanha & Carta \\
\hline Aris Alexandrou & Grécia & Poema \\
\hline Amy Lowell & EUA & Poema \\
\hline $\begin{array}{l}\text { Arthur Rimbaud/ Paul } \\
\text { Verlaine }\end{array}$ & França & Poema \\
\hline David Berman & EUA & Poema \\
\hline Gustavo Adolfo Bécquer & Espanha & Poema \\
\hline Heiner Müller & Alemanha & Poema \\
\hline Jeannette Lozano & Itália & Poema \\
\hline Antonio Machado & Espanha & $\begin{array}{l}\text { Prosa } \\
\text { (fragmentos) }\end{array}$ \\
\hline Friedrich Schlegel & Alemanha & $\begin{array}{l}\text { Prosa (excertos } \\
\text { sobre poesia) }\end{array}$ \\
\hline
\end{tabular}

Se há essa busca de heterogeneidade espacial e temporal, há também uma ressalva feita por Manuel de Freitas: "Não temos editado muitos poetas com menos de 30 anos" "Não aparecem naturalmente com a qualidade que o justificasse e não vale a pena estar a inventá-los..." (QUEIRÓS, 2015). Ou seja, a revista tem um forte teor crítico a guiar suas escolhas. Mas, mesmo com a heterogeneidade dos colaboradores, há a compreensão de um princípio que une todos esses participantes, "elementos comuns, de laços, de cumplicidades" (CAMARGO, 2013, p. 10), o que pode ser sintetizado talvez na ideia de atrito, de resistência que a poesia mantém como discurso insubmisso. Tais vozes não formam 
um grupo nem movimento, dada a pluralidade de ideias, formas, dicções e temas, no entanto a presença dessas vozes articuladas em conjunto ${ }^{28}$ fica evidente ao longo da leitura dos textos, com a utilização de formas de endereçamento (dedicatórias, epígrafes, referências internas, etc), além é claro das recensões críticas (principalmente, as de Manuel de Freitas, presentes no seu livro Incipit, reunindo resenhas de livros que impactaram, segundo seu ponto de vista, o cenário poético português) as quais, muitas vezes, comentam obras dos autores que colaboram na revista. A recensão além de ser um convite à leitura para além do espaço da revista, é também um meio "de formação literária, tanto dos colaboradores como dos leitores de uma revista". ${ }^{29}$

Outro levantamento mais abrangente, baseado na análise dos vinte e três números da revista, bem como no site da Averno, comprova a ideia de que os nomes presentes nas edições são recorrentes. É relevante notar que alguns nomes aparecem com uma certa constância. Deixam de aparecer nessa revista muitos outros poetas valorizados ou reconhecidos pela crítica universitária ou jornalística, como, por exemplo, Gastão Cruz, Nuno Júdice, Luis Quintais e Pedro Mexia. Esse apagamento de nomes corresponde a uma declaração de não interesse, um gesto fortemente crítico, portanto. Entre os nomes mais recorrentes, em poesia e/ou prosa (prosa literária ou crítica), excetuando o casal editor Manuel de Freitas e Inês Dias, destacamos: Joaquim Manuel Magalhães, Adília Lopes, António Barahona, A.M. Pires Cabral, Fátima Maldonado, João Miguel Fernandes Jorge, Gil de Carvalho, Rui Pires Cabral, Silvina Rodrigues Lopes, José Miguel Silva, Fernando Guerreiro e Jorge Roque. Esse

\footnotetext{
$\overline{28}$ Para além desses aspectos, observamos também a formação de um grupo através dos livros editados pela Averno, uma vez que, em sua maioria, seus autores são os mesmos presentes na revista.

29 Clara Rocha, Revistas literárias do século XX em Portugal, p. 59.
} 
destaque de nomes nos leva a concluir como os poetas de 70, com obra ainda em movimento, como Joaquim M. Magalhães e João Miguel Fernandes Jorge, convergem em ideias ${ }^{30}$ com as duas revistas Cão Celeste e Telhados de Vidro e como críticos como Silvina Rodrigues Lopes e Fernando Guerreiro dão o tom reflexivo sobre literatura e seu confronto com o mundo. Constituise assim um diálogo interno muito forte, muito articulado entre nomes de experiência sedimentada e autores mais novos. Há um compromisso "po-ético" entre eles. Se há linhas temáticas de larga tradição lírica como tempo e finitude, a experiência amorosa e a indagação sobre a palavra poética, tais semânticas são ressignificadas para o espaço da vida urbana contemporânea, massificante e distópica. Outra linha temática destacável é o lugar da arte - em especial da poesia - e, consequentemente, do poeta/artista no mundo atual. Ou seja, as cenas de escrita e de leitura são fortemente auto-reflexivas e críticas sobre a contemporaneidade: "A poesia, a arte, voltando-se para elas mesmas, por um movimento ao qual os tempos não são alheios [...]" ${ }^{31}$. Outro aspecto a enfatizar é a prática de apropriação tão recorrente na poesia pós anos 80 . O diálogo interno e externo entre poemas e poetas se faz em muitas direções, deslocando-se vozes como as de Camões, Cesário Verde, Fernando Pessoa e Álvaro de Campos.

\footnotetext{
30 No texto jornalístico "Uma revista com qualidades" já citado anteriormente, publicado no suplemento Ipsilon, do Jornal Público (QUEIRÓS, 2015), há uma passagem interessante: “[...] quando mostraram a Gaspar o projecto da Telhados de Vidro, este diz ter-se lembrado dos esforços de Vitor Silva Tavares para ressuscitar, em meados dos anos 80, a velha revista \& etc, que dirigira em 1973 e 1974. "A Telhados de Vidro tem uma personalidade bem vincada, mas acho que há uma espécie de passagem de testemunho, como se a revista que Vitor Silva Tavares não conseguiu fazer nos anos 80 se tivesse materializado de outra forma 20 anos mais tarde", disse ao Ípsilon, sem saber que o histórico editor de Herberto ou Luiz Pacheco já só teria um dia de vida. Mas se o espírito da \& etc pode ter ressurgido na Telhados de Vidro, talvez seja legítimo encontrar um precedente mais próximo na efémera revista As Escadas Não Têm Degraus, que António M. Feijó, João Miguel Fernandes Jorge e Joaquim Manuel Magalhães dirigiram para a Cotovia entre 1989 e 1991. O formato e a organização têm algumas afinidades e as duas publicações partilham vários autores."

31 Blanchot, O livro por vir, p. 297, 2005.
} 
Esta preocupação com o tempo em que se vive, manifestase, também, nos ensaios. É o que pode ser observado, por exemplo, em: "A anomalia poética" $\left(\mathrm{n}^{\circ} 1\right)$ que reflete sobre o lugar da poesia, no mundo capitalista atual; "A especialização em Literatura (e outras artes)" (n` 4 ) que medita sobre o processo de especialização e fragmentação nas Artes, cada vez maior, no mundo contemporâneo; "O declínio da poesia" $\left(n^{\circ} 6\right)$ que pensa acerca do processo de secundarização da poesia desde os seus primórdios - ainda extremamente ligada a música - até os dias de hoje. Também há textos que discutem mais detidamente sobre determinadas poéticas: "Memória da cidade" (n²) que discute o lugar da memória na poesia de Camões e de Camilo Pessanha; "Luís Miguel Nava: Hard poetry" $\left(\mathrm{n}^{\circ} 18\right)$ que reflete sobre a presença do corpo na poesia de Luís Miguel Nava e de Álvaro de Campos; "Um homem só" ( $\left.n^{\circ} 12\right)$ que pensa a poesia de António Nobre. Além desses ensaios sobre poéticas, há outros sobre as artes visuais e plásticas, um veio iniciado fortemente por Jorge de Sena, com seu Metamorfoses (1963), e que João Miguel Fernandes Jorge, como poeta e crítico de arte continuou admiravelmente com voz própria. Vemos assim como Telhados de Vidro é uma revista firmemente contemporânea, pensando a poesia como opção pessoal cada vez mais necessária. Ao misturar vozes de diferentes gerações ${ }^{32}$, sem hierarquias ou explicações, esse deliberado gesto crítico ressalta, em consonância com Agamben (2009), que o contemporâneo é aquilo que permanece atual.

As manifestações escritas de Manuel de Freitas, a voz editorial de Cão Celeste e Telhados de Vidro”, em entrevistas ou textos críticos ou comentários em blogs e outros espaços de

32 Por exemplo, de A.M. Pires Cabral que estreou na década de 70, de Rui Baião que estreou na década de 80, de Miguel Martins que estreou em 95, além é claro de alguns nomes da dita geração 00 de Manuel de Freitas 
comunicação com os leitores, acabam por sinalizar a necessidade constante de atritar cenas de escrita e cenas de leitura. Tais revistas, portanto, contribuem fortemente para problematizar com inteligência o panorama português de produção poética (mas também o nosso, por deslocamento....), tanto no âmbito da realização de poemas, quanto na exposição crítica e ensaística, bastante atentas que são ao tempo de agora, com seu entrecruzamento de textualidades, suas demandas, suas tensões, diversidade de meios e modos de criação.

\section{Referências}

\section{AGAMBEN, Giorgio. O que é o contemporâneo? E outros} ensaios. Tradução Vinícius Nicastro Honesko. Argos: Chapecó, 2009.

BLANCHOT, Maurice. O livro por vir. Tradução Leyla Perrone -Moisés. Martins Fontes: São Paulo, 2005.

CABRAL, Cleber Araújo; LIMA, Sérgio Henrique da Silva. Roteiro de variações: entrevista com Manuel de Freitas. Em tese, Belo Horizonte, v.20, n³, p. 250-257, 2014.

CAMARGO, Maria Lucia de Barros. Por que ainda lemos revistas de poesia? Apontamentos para o estudo da poesia brasileira em suas revistas. Boletim de Pesquisa NELIC, Florianópolis, v.13, p. 5-14, 2013.

CAMARGO, Maria Lucia de Barros. Revistas Literárias e Poesia Brasileira Contemporânea. Boletim de Pesquisa NELIC, FLORIANÓPOLIS, v. 4, p. 5-12, 1999.

CAMARGO, Maria Lucia de Barros. Dos poetas e/em suas revistas. In: Célia Pedrosa; Ida Alves. (org.). Subjetividades em devir: estudos de poesia moderna e contemporânea. 1ed.Rio de Janeiro: 7Letras, 2008, v. 1, p. 226-238. 
CÃO CELESTE. Lisboa: Averno, n. 1, 2012 / n. 13, 2019.

COSTA, Paula Cristina. O clássico e o contemporâneo, hoje, em alguma poesia portuguesa contemporânea. Abril Revista do Núcleo de Estudos de Literatura Portuguesa e Africana da UFF, vol. 7, n 15, p. 219-224, 2015.

Editora Averno. Disponível em: $<$ http://editora-averno. blogspot.com/ >. Acessado em: 27/09/2020.

FREITAS, Manuel. Incipit. Lisboa: Averno, 2015.

MAFFEI, Luis. Poetas sem qualidades: em busca da contemporaneidade possível. Textura, Canoas, $\mathrm{n}^{\circ} 14$, p. 5-14, 2006.

PIRES, Daniel. Dicionário das revistas literárias portuguesas do século XX. Lisboa: Contexto, 1986.

QUEIRÓS, Luís Miguel. Uma revista com qualidades. Jornal Público (ipisilon livros). Disponível em: < https://www. publico.pt/2015/09/25/culturaipsilon/noticia/uma-revista-comqualidades-1708625 > . Acessado em: 21/09/2020.

RELÂMPAGO revista de poesia. Lisboa: Fundação Luis Miguel Nava, nº 1, 1997 / 39-40, 2017.

Revista Intervalo. Disponível em: $<\mathrm{http}: / /$ revistaintervalo. tumblr.com/ >. Acessado em: 20/09/2020.

ROCHA, Clara. Revistas Literárias do século XX em Portugal. Imprensa Nacional- Casa da Moeda, 1985.

SILVESTE, Osvaldo; SERRA, Pedro. Século de Ouro. Antologia Crítica da Poesia Portuguesa do Século XX. Lisboa: Cotovia, 2002.

TELHADOS DE VIDRO, Lisboa: Averno, $\mathrm{n}^{\circ}$ 1, $2003 / \mathrm{n}^{\circ}$ 22, 2017.

WATSON, Leonor Paiva. Livraria Poesia Incompleta reabre já ao virar da esquina. $\boldsymbol{J} \boldsymbol{N}$. Disponível em: <//www.jn.pt/ artes/interior/livraria-poesia-incompleta-reabre-ja-ao-virar-daesquina-9953564.html>. Acessado em: 27/08/2020. 
WEINTRAUB, Fábio. Um fato no limite da nudez: entrevista com Manuel de Freitas. Disponível em: $<$ https://escamandro. wordpress.com/2017/12/10/um-fato-no-limite-da-nudezentrevista-com-manuel-de-freitas-por-fabio-weintraub/>. Acessado em: 20/09/2020. 